\title{
The Isolation of Upper Management
}

\author{
A. Richard Krachenberg, John W. Henke, Jr., and Thomas F. Lyons
}

$\mathrm{D}$ espite having been discussed for years, the problems of centralization, autocratic management style, and poor communication linkages between top management and the rest of the firm still plague American business. A key reason why these problems still exist is because they are discussed as separate issues and in an excessively simplistic manner. They are, in reality, a manifestation of interrelated causes and must be dealt with as such.

Because there is more than one cause, there is also more than one solution, and they too are interrelated. The atypical solution is to decentralize decision making. When applied singularly and carried to an extreme, it can cause an organization to suffer from a loss of lateral coordination without reducing upper management's sense of isolation. However, when decentralization is combined with enlarging the spans of control of most managers and having top managers accept the responsibility for more two-way communication with lower level managers, a very different situation evolves. Decentralization allows upper managers more free time to talk with, and listen to, lower levels. Larger spans of control reduce the number of vertical levels while broadening each one. This in turn facilitates developing informal groups and teams. Still, the solution does not end here, for these actions need the support of very different evaluation processes and reward systems. Current systems need restructuring.

The problem of upper management isolation never will be eliminated. Not one of the proposed individual solutions singularly will solve the problem. However, all of them in combination can reduce it to a manageable size.

\section{An Example}

For 14 months, Don Nervy, a middle manager, at a large international manufacturing firm, had been exploring, with his counterparts at other firms in the industry, the feasibility of establishing industrywide product quality standards. His manager supported this initiative-a hot topic in the industry.

Nervy was subsequently able to include in an upcoming annual supplier survey a series of questions on quality standardization issues. As

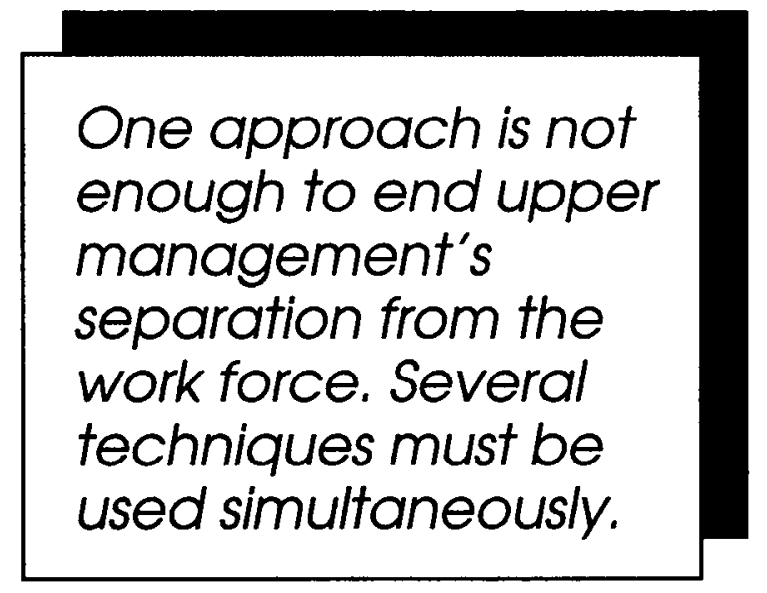
is the standard prac-

tice in his firm, Nervy and his manager presented the final draft of the survey to their vice president for his approval. The VP immediately reacted to the quality-related questions, stating that they were inappropriate and should be deleted from the survey. After considerable discussion, the VP was reluctantly convinced that the questions should be left in the survey, albeit with several modifications.

Why, after all of Nervy's time and effort, did the VP want to throw out the quality-related questions? Was it because he was opposed to industry-wide standards? Did he have knowledge of some company strategy or other top management concerns that would negate or preclude such standards? Was he a disciple of the NotInvented-Here syndrome? Why, after 14 months of involvement, had Nervy and his manager not informed the VP of their endeavors in establishing industry-wide quality standards? Why was there such a wide communication gap between the VP and his subordinates?

The consultants working with Nervy on the customer survey experienced additional incidents. The VP was to sign the cover letter accompanying the survey. Naturally, he asked that a 
proposed draft be written and submitted to him for final approval before he signed it. The consultants initially provided a draft letter to one of Nervy's subordinates. The subordinate revised the draft several times, working continuously with the consultants, until they completed a mutually acceptable letter. Nervy, who then reviewed it, became dissatisfied. He therefore made several changes, and sat down with his subordinate to write another draft, which they completed after further input from the consultants.

When Nervy went to his manager with the letter, they revised it again. At this point, the letter had been substantially rewritten four times, each time having gone through numerous revisions, and had involved three individuals representing three levels of the organization's hierarchy.

When the VP eventually saw the letter, he didn't like it. He therefore suggested drastic revisions. Nervy's subordinate made the revisions, after which he informed the consultants that the letter was ready. Upon seeing it, the consultants suggested that the approved content and tone of certain sentences in the letter could have substantial negative effects on the survey response rate. Although Nervy and his manager were extremely reluctant to do so, they revised the letter again, and presented it to the VP with a carefully prepared explanation. After one final set of changes that the VP suggested, the survey cover letter was ready for mailing. The whole sequence included nine major revisions involving an untold number of hours over a four-week period.

The firm in which these events occurred is among the top 15 Fortune-ranked manufacturing firms and an international leader in its industry. The industry, which is intensely competitive, includes an extremely capable array of both foreign and domestic competitors.

\section{So Much Written, So Little Heard!}

What we have described here is not unique to this firm. It is a common phenomenon in many large manufacturing organizations. As a result, management experts have written about it numerous times, suggesting an even larger number of solutions. Nevertheless, further discussion is still needed for several major reasons. First, the phenomenon is still pervasive around the world. It therefore needs continual exposure in the literature. Second, as mentioned previously, it is not a single problem, but a manifestation of many interrelated causes usually discussed in overly simplistic terms.

Third, solutions and answers tend to be overly simplistic. In the situation above, one typically proposed solution is to have more frequent communication between levels. Other experts would suggest that the VP should decentralize certain decision-making activities and push more authority and responsibility down to lower levels in the organization. Alternatively, Drucker (1988) has noted that manufacturing firms hoping to continue to be viable in increasingly worldwide competition must flatten their organizational structures. Although separate and independent of one another, these solutions are intertwined. Worse yet, they are interrelated with several other variables. Consequently, these types of situations need a much broader perspective than usual if management is to implement a solution

Fourth, few top managers recognize or acknowledge the presence of this situation in their organization. This compounds the complexity of the problem. On the other hand, lower managers are acutely aware of the situation but maintain that it is a significant and integral part of their responsibilities to protect their managers from an overload of information and work.

Fifth, from a parochial and nationalistic viewpoint, many American manufacturing firms suffer from this situation. Yet these firms are engaged in a competitive battle in which they need every advantage they can muster. On a project similar to the example above for a Japanese transplant in the same industry, a survey of the same complexity underwent two revisions and a cover letter was revised only once. American management cannot afford to be cavalier toward occurrences of this type.

\section{THE PROBLEM}

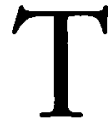
he core element of this problem can be stated succinctly. Over time, the top levels of management tend to become isolated

from the rest of the organization. A chasm develops that results in a gap in communication, mutual understanding, acceptance of new ideas and knowledge, and even faith and trust of those on both sides.

In most situations, top management usually receives filtered input that subordinates have carefully screened several times. However, top management needs more information and data, more qualitative input, and less formal analysis than it receives. Lower levels require more information from the top. More important, they need a general and, sometimes, a specific sense of direction and support. Yet all they typically receive are directives about specific situations. Even with filtered input, the top feels overburdened 
and alone. Lower levels concurrently feel underutilized, yet they fill up their office hours with make-work projects and double-checking on their subordinates, uncertain whether or not they will be shot down if they exercise initiative.

\section{THE CAUSES}

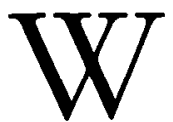

hat brings about this strange and debilitating set of circumstances? There is no single clear cause. Additionally, the problem area can be approached from a variety of positions. However, because the top of the organization sets the tone throughout, we will start there.

\section{A Heavy Workload}

The upper levels in any manufacturing organization are extremely busy. They work long hours while interacting with people both inside and outside the firm. They gain access to information not available to lower levels-much of which should be shared with these levels. They also need much information and input from lower levels because they are far removed from the marketplace and the daily operations."

\section{Overwhelmed with Information}

In highly volatile, dynamic environments, the volume of information top managers process is so great they are literally overwhelmed. As a result, they have less time to listen to people and to gather and assimilate or disseminate information. The frequently adopted solution is obvious: reduce the input. The manner by which a top manager does this is also obvious: surround oneself with a staff that acts as a buffer and condenses and filters information going to the boss. Initial filtering consists of abbreviating the input and presenting it in summary form. Over time, there is often an increasing tendency to filter out or tone down information that the staff perceives as disturbing or distracting to superiors. The isolation of the manager begins at this point.

Because the top of the organization affects the whole organization, lower levels begin adopting the same strategy to varying degrees in dealing with their bosses. To adopt an Old World proverb, this proves once again that, as some organizational cynics would say, "A fish rots from the head first." Eventually, every level is overly concerned with the content and format of the information to be passed upward.

\section{Autocratic Leadership Prevalence}

A leadership style that is somewhat autocratic with a tendency toward centralized decision mak- ing exacerbates the isolation problem. With such a leadership style, top managers want to become involved in many decisions, make them, and possibly even implement them in some detail. As a result, they become even more pressed for time. This in turn forces them to use even more filtered information and be more selective in who sees them and for how long. A concomitant behavior is to give more directives, see fewer subordinates, and listen even less. This is a setting in which selective information flows up and only directives flow down. The isolation of top management is now complete.

\section{Small Span of Control}

As a result of high centralization, there will often be a relatively small span of control at the top of the organization-top people will have very few direct "reports." Contrary to what appears to be obvious, the small span of control also leads to the isolation of top management. With fewer people reporting to a manager, more time is available for the manager to do work-theoretically. In reality, hands-on managers now have more time to direct, get involved with, and more closely manage the work of all their direct subordinates. In addition, because the size of the span of control directly affects the number of hierarchical levels, a narrower span of control means more levels. This means that information traveling up and down the organiza-

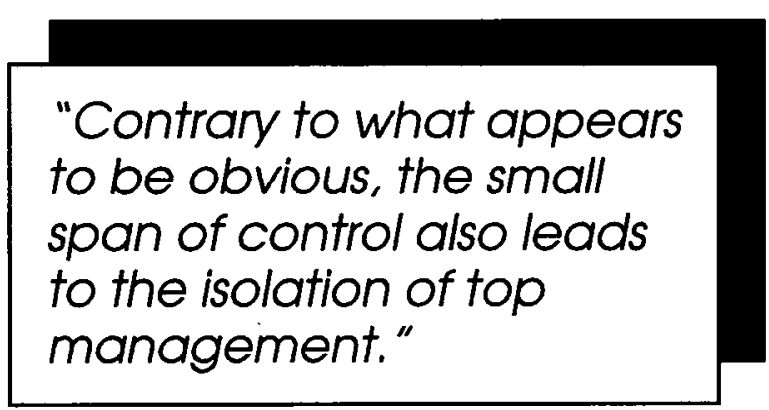
tion takes longer to arrive at its destination. Moreover, it is passed through more filters in the process, becoming even more distorted.

In multi-level organizations, where meaningful decision making is largely carried out at the top, most lower managers spend too much time looking up the hierarchy instead of concentrating on their work and on the environment around them. The end result is these firms do not take full advantage of the capabilities and knowledge of personnel at lower levels. Consequently, top management does not make optimal decisions, thereby reducing its competitive advantage.

An outsider viewing this situation could unsympathetically say that it is of the manager's own making and that, as such, he or she should deal with it. This may often be true, but saying it does not solve the problem. The situation may be inherited by the manager or be the result of systemic factors beyond a single manager's individual degree of discretion. 


\section{COMMON SOLUTIONS}

$\mathrm{H}$

ow can the negative aspects of this situation be minimized? First, all of the isolation problems noted can never be completely eliminated. Some amount of isolation of top management is inevitable; it goes with the position. Meaningful recommendations, therefore, can alleviate the symptoms, not the condition.

\section{Decentralize Decision Making}

Suggestions often focus on decentralizing decision making by giving lower levels (middle management) more independence and freedom to act independently. This has been a major component of IBM's attempts to cure the isolation of its top management ("The Big Winners ..." 1991). The suggestion is valid in many situations; lower levels in most firms are able to do much more, better and faster,

"Some amount of isolation of top management is inevitable; it goes with the position." than higher levels because they are closer to the issues. As long as lower levels are staffed with competent people, most firms can improve the quality and pace of decision making with some decentralization. If firms attempt to reduce costs and increase efficiency even further by reducing organizational levels, they may be forced to increase the competency of their staffs with training and recruitment. Decentralization, which is not the only remedy, has a price with at least two dimensions. First, it makes it much harder to achieve coordination and consistency across various units. Where these two conditions are crucial, the price may be too high. IBM is cognizant of the threat of decentralization to compatibility among its different computer lines. The company plans to coordinate its many different computers and software, although pursuing industry-standard software may be cheaper.

Second, decentralization, in its purest form, precludes top levels from having input on some issues. Decentralization is good when it frees upper management from being involved in what can be more easily handled at lower levels and what will not benefit from top management involvement. However, when only top management has access to sources or types of information unknown to the lower levels, and when the issues involve basic corporate policy, then once again decentralization may be inappropriate.

\section{Differentiate Information Flow}

What, then, can be done? Several options are available, but none of them are easily achieved or easily sustained. A somewhat mechanistic but still useful first option is for every level in the organization to attempt to distinguish clearly between issues that can be decided at lower levels and those that need to be sent to upper levels. Over time, however, more and more issues will move upward, unless the upper level makes a determined, conscious, and consistent effort to resist the inclination to be involved in and respond to everything sent to it.

\section{Institute Top-Bottom Interaction}

A more viable option contains several parts. The underlying element is for the organization to commit to having both decentralization and upper management involvement. Note that we choose to call it neither "control" nor "centralization," but "top-bottom interaction" or "involvement." The top encourages and rewards decentralization of decision making. The top also must legitimize two-way communication, and be willing not only to seek input from lower levels but also to listen more.

The concept of "management by walking around" (MBWA) espoused so vigorously by Peters and Waterman (1982) exemplifies what we are discussing here. However, it involves more than walking around and listening: it involves being willing to legitimize new viewpoints by making time available for listening to others and by sharing information and responding to their new ideas. Hopefully, the major result is an increase in trust by both upper and lower levels of eách other's competence and good intentions. Trust, combined with competent delegation, can do much to reduce problems of top management isolation.

In the opening vignette, Don Nervy and his boss would have been wise to telegraph to the VP their interest in exploring industry cooperation. Because it was becoming an industry-wide matter of discussion, the VP certainly should have been willing to listen to and share ideas on the topic with his subordinates. That this did not happen suggests the existence of too much rigidity in the organizational hierarchy-either too little communication in either direction or too much top-down communication and an implied "don't bother me too much in-between."

\section{Increase Span of Control}

In an organization with a fairly extended vertical hierarchy (many levels in the organization from top to bottom, especially in the middle management sector), the practice of MBWA and related efforts to pick up the tempo of communication becomes somewhat attenuated because of the excessive number of levels to be penetrated. By 
widening the span of control of each manager, the number of levels in the vertical hierarchy can be reduced.

The effect of this manipulation of span takes a tall, relatively narrow pyramid and turns it into a much shorter and broader structure with no necessary change in the number of people in the total organization. With fewer levels, the top and bottom are closer to one another organizationally. If the top of the organization legitimizes some of what was suggested above, top and bottom will become closer operationally as well. Further, the act of widening spans of control tends to bring about de facto decentralization because each manager now has too many reporting subordinates to supervise them all as closely as before.

The common solutions outlined here tend to fail to solve problems of isolation. We believe this is partly a result of their frequently half-hearted and faulty implementation. For example, many experienced organization watchers (cynics) have publicly questioned whether IBM's recent maneuvers to decentralize will go far enough to cure the ills of Big Blue. These solutions may be common; however, like common sense, they are seldom seen. Yet they are also critical; small doses may not be sufficient to cure a major illncss. We also believe they fail partly because they are necessary but not inherently sufficient. To be successful, they must be combined with less common elements in a more integrated approach.

\section{UNCOMMON SOLUTIONS}

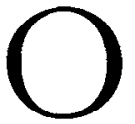

ur recommendations thus far have dealt exclusively with vertical elements in the organization. At this point, most suggestions dealing with this topic stop. That is why, even when fully implemented, they provide only a partial solution to the problem. They have failed to consider one further organizational structure variable: lateral relationships, with a need for cooperation and horizontal and vertical information sharing.

\section{Lateral Relationships}

We noted that a problem with decentralization is the possibility of less cooperation and interaction laterally in the organization. With increased spans of control and the subsequent lower amount of coordination carried out by direct supervision, there is this same void. How should a firm respond?

Contemporary management literature is filled with studies, descriptions, and exhortations abou't the benefits coming from using permanent or temporary teams. At the very least, the literature recommends using facilitators, integrators, or a formal liaison person. Each of these formal lateral organization design mechanisms has its place; in a more complex and dynamic environment, their value and worth rises.

\section{Horizontal Relationships}

The truly flexible organization becomes so not simply by formalizing lateral processes, but by legitimizing and encouraging both horizontal and diagonal relationships. Upper management must encourage middle managers to establish informal lateral relations and become acquainted with others opposite themselves within their own function or product area, and across multiple product, functional, and geographic areas. Rewards must be given for taking these steps. There must be more informal vertical and horizontal communication across the organization. There is no need to wait for a common boss to pass information formally from one department or sector to another.

\section{Informal Groups}

With wider spans of control, informal leaders or opinion lcaders and focal points should be encouraged to come into being and facilitate the process of mutual adjustment across a given level of the organization.

With the development of informal groups, an upper manager has the opportunity to interact not simply with key individuals on lower levels, but with individuals who have knowledge of other groups' thoughts and beliefs. When upper management passes on information, it then goes to a network of people. When upper management is seeking support for new thrusts, or changed initiatives, it then has the opportunity to build coalitions to bring about a focus of thought on the issues and receive meaningful feedback as well.

\section{ADDITIONAL UNCOMMON SOLUTIONS}

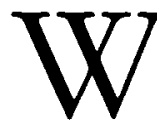

e have been talking about top management initiating specific changes in its structural design, leadership style, and internal communication processes. Once such a process has begun, there are two other major internal variables that should be adjusted. Moreover, an external communication activity can be initiated. 


\section{Figure \\ Structural and Process Remedies to Reduce Top Management Isolation}

Formal

Flatten organization

- fewer levels

- increased span of control

Decentralize decision making

Change control and

evaluation systems

Set up cross-functional teams

Change reward structures
Informal

Manage by walking around-talking and listening

Share decision making-lateral and vertical

Set up informal networks

Train in new processes

Increase tempo of communication activities

Use third-party consultations

\section{Sharing Controls with Lower Management}

In a highly developed vertical hierarchy with a concomitantly high level of centralized decision making, control systems typically are very centralized as well. Structure design changes mean that control and information systems must change also. More information must be shared with more people because of the increased participation of more individuals in the decision-making processes. Lower-level managers should be evaluated on different criteria as well.

\section{Reward Accordingly}

Reward systems and processes also must be changed. Specifically, this means using more result-based evaluations. Individuals should be rewarded not only on how well they do what they are told to do, but also on the decisions they make and the results they achieve. Further, when teams are formed, serious consideration must be given to using peer evaluations and team-based rewards. If people are not rewarded in some way for changing their behavior, then the suggestions summarized in the Figure will be ineffective.

\section{Take a "Professor" to Lunch}

The isolation of management occurs with more than just subordinates. Over the years we have noticed that as individuals move up the hierarchy of their organization they also tend to isolate themselves from outsiders who in the past acted as a sounding board for ideas, a source of unbiased insights into issues and concerns, a reservoir of new thoughts, or even a gadfly raising somewhat uncomfortable questions and issues. A board of directors might serve these functions, but practical and political considerations often vitiate these activities and their benefits.

These uninvolved outsiders tend to be individuals who are highly respected by managers and are recognized as having no personal gain to realize by virtue of how they interact with the manager. Often the outsider is a former mentor, a former professor, a consultant, or an older, more experienced acquaintance from outside the firm. By meeting with the outsider every three to six months in an informal environment, such as lunch or dinner, the manager has the opportunity to obtain a disinterested third-party opinion. A conscious effort to maintain such relationships can only benefit the manager.

I $\mathrm{n}$ the dynamic, ever-changing competitive environment of the twenty-first century, the more successful industrial organizations will be those that concern thenselves not only with the substantive elements of products and strategy, but also with the processes of management. It is not enough to have a good product and a concomitant good implementation strategy. Even more important is to have a flexible management style that stresses good organization-wide interactions and rapid communications in multiple clirections. This supports the ability of upper management not only to give orders, but to maintain rapport with lower levels and therefore build and change plans faster, and build coalitions of understanding and support around these plans.

Upper managers cannot make such processes work if they are isolated, if they do not hear or listen well, and if they spend time only passing orders down through layers of management. We have suggested some structure, communication, and leadership style changes supported by changed control and reward systems that can move an organization in the right direction.

Individually, these ideas are not new. However, they have not been discussed frequently in combination. More important, either individually or in combination, they have seldom been heeded. Any single idea may have some limited impact on the phenomenon of upper management isolation. However, each of them tends to support and buttress one another, so in combination they multiply thcir individual effects.

Each also has its costs and limitations in any one specific organization. No organization may be able realistically to support or even tolerate a broad attack on the problem using all of these techniques or tactics. An organization will have to choose a combination tailored to its own needs and resources. Our major point is that a onesolution treatment will not work. Some combination of these mutually reinforcing tactics is necessary to reduce the syndrome of top management isolation and its debilitating effects. Neither will a one-time approach work. Upper management 
must be unceasing in its efforts to resist and overcome the isolation syndrome. $\square$

\section{References}

"Abe Peled's Secret Start-up at IBM," New York Times, December 8, 1991, Section 3, pp. 1+.

"The Big Winners in Big Blue's Breakup: Customers," Business Week, December 23, 1991, p. 28.

Peter F. Drucker, "The Coming of the New Organization," Harvard Business Review, January-February 1988 , pp. 45-53.
Thomas J. Peters and Robert H. Waterman, Jr., In Search of Excellence (New York: Harper \& Row, 1982).

A. Richard Krachenberg and Thomas F. Lyons are professors of management at the University of Michigan-Dearborn. John W. Henke, Jr. is an associate professor of marketing at the School of Business Administration, Oakland University, Rochester, Michigan. 